\title{
IV. On certain phænomena of voltaic ignition and the decomposition of water into its constituent gases by heat
}

\author{
W.R. Grove Esq. M.A. F.R.S.
}

To cite this article: W.R. Grove Esq. M.A. F.R.S. (1847) IV. On certain phænomena of voltaic ignition and the decomposition of water into its constituent gases by heat, Philosophical Magazine Series 3, 31:205, 20-35, DOI: 10.1080/14786444708645776

To link to this article: http://dx.doi.org/10.1080/14786444708645776

曲 Published online: 30 Apr 2009.

Submit your article to this journal $\pi$

Џll Article views: 2

Q View related articles $₫$ 


\section{[ 20$]$}

IV. On certain Phanomena of Voltaic Ignition and the Decomposition of Water into its constituent Gases by Heat. By W. R. Grove, Esq., M.A., F.R.S.*

IN the Philosophical Magazine for August 1841, I recom1 mended for eudiometrical purposes, the use of a platinum wire ignited by a voltaic battery. In fig. 1 is re- Fig. 1. presented a form of apparatus for this purpose; it consists of a tube of Bohemian glass, with a loop of platinum wire $\frac{1}{80}$ th of an inch diameter sealed into its upper end; the size of the glass tube may be adapted to the quantity of gas sought to be analysed, and may when necessary be reduced to extremely small dimensions, one-eighth of an inch being ample; into this the gas may readily be made to ascend, by the insertion of a wire of copper, platinum, or glass, as may be suitable to the gas: two cells of the nitricacid battery are sufficient fully to ignite the wire, and the same battery supplies, by electrolysis, pure oxygen and hydrogen for the analysis. Since the

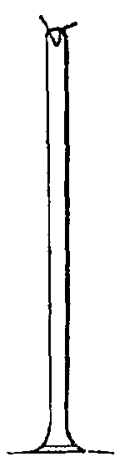
period when I first proposed this, I have seldom used any other apparatus for such gaseous analyses as are performed by combining the gas to be examined with oxygen or hydrogen. This eudiometer possesses the advantage of enabling the operator either to detonate or slowly to combine the gases, by using different powers of battery, by interposing resisting wires, or by manipulation alone,-a pract ised hand being able by changing the intervals of contact to combine or detonate the gas at will. My general practice has been to produce a gentle heat in the wire until the gases contract, and then gradually to increase the heat until a full ignition takes place, by which means all the objects of the eudiometer of Volta are fulfilled, without detonation, without dependence on the fickle electric spark, and without thick tubes, any danger of explosion, or of the gases being projected from the eudiometer.

I have commenced with a description of this eudiometer, as it has been indirectly the means of my undertaking the experiments detailed in this lecture; and as its very great convenience has never been generally understood, I think that in strongly recommending it, I shall be of service to chemists.

In a paper honoured by insertion in the Philosophical Transactions for 184.5, p. 358 , I have shown another method of eudiometry also performed by voltaic ignition; in that experiment the vapour of camphor was decomposed into carbonic oxide and carburetted hydrogen; it was an application

* From the Philosophical Transactions for 1847, part i.; having been received by the Royal Society September 3 , and read November $19,1846$. 
of voltaic ignition to effects analogous to those produced by Priestley and others, by passing compound gases through ignited tubes of porcelain.

But the voltaic process has this immense advantage, that the heat can be rendered incomparably more intense; that the quantity of vapour or gas to be operated on may be indefinitely small; that there are no joints, stop-cocks or ligatures; and that there is no chance of endosmose, which takes place through all porcelain vessels. I therefore determined to examine by these means several gases, both with a view of verifying, under different circumstances, known results, and seeking for new effects by this new and advantageous application. I used an eudiometer (fig. I) of 8 inches long and 0.4 inch internal diameter, exposing the gases to intense heat, and subsequently analysed the residues in one of the same length, but 0.2 inch diameter.

I will first consider the physical effects of different gases on the ignition of the wire itself.

In a paper on the Application of Voltaic Ignition to lighting Mines*, I have mentioned the striking effects of hydrogen in reducing the intensity of ignition of a platinum wire, so much so that a wire voltaically ignited to incandescence in atmospheric air, is apparently extinguished by inverting over it a jar of hydrogen; with other gases the effects are not so striking, and with them these differences are best shown by including a voltameter in the circuit. Davy found that the conducting power of a wire diminished in proportion to the degree to which it was heated : assuming the accuracy of this position, the amount of gas in the voltameter would be inverse to the intensity of ignition in the wire. The following is the result I obtained with different gases, employing the same battery (the nitric-acid combination at its most constant period), the same wire, and the same vessel :-

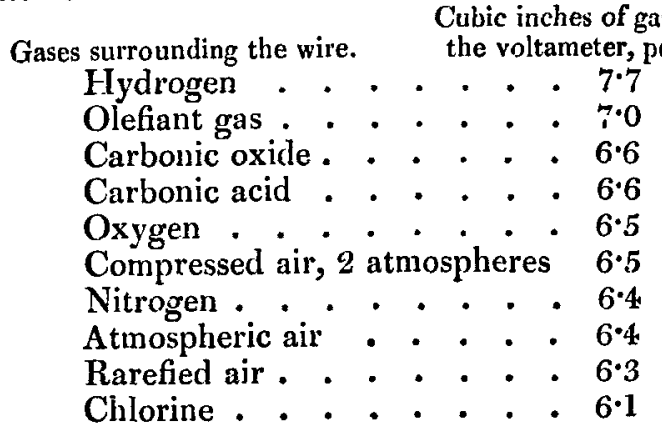

- Phil. Mag. Dec. 1845. 


\section{$22 \mathrm{Mr}$. Grove on the Decomposition of Water by Heat.}

To ascertain the relation between the amount of radiant heat generated by the same battery and wire in gases which presented striking differences as to the luminious effects of the platinum wire, an apparatus was prepared in which the bulb of a thermometer was retained at a certain distance from the coil of wire ignited by a battery of four cells, and exposed, first, to an atmosphere of hydrogen, and then to one of atmospheric air, at the same temperature and pressure; the thermometer rose $7 \frac{1}{2}^{\circ}$ in five minutes in the hydrogen, and $15^{\circ}$ in the air in the same time. Both the heating and luminous effects appear therefore to be greater in atmospheric air than in hydrogen. I cannot satisfactorily account for the differences shown in the above table; there appears a general tendency to greater ignition in the electro-negative than in the combustible gases, but the facts are far too few to found a generalization. I was at first inclined to regard the difference of effect in hydrogen as analogous to the peculiarity mentioned by Leslie* respecting its convection of sound, but the parallel does not hold; sound is transmitted imperfectly through rarefied air, and also through hydrogen; on the contrary, the heat of the ignited wire is most intense in the former, and least so in the latter; the heat is also very much reduced in intensity in the compounds of hydrogen, ammonia and olefiant gas, or even by a small admixture of hydrogen with another gas, such as nitrogen; hydrogen, therefore, appears to have a peculiar and specific action in this respect.

I now pass to the consideration of the effects of the ignited wire on different gases. The ignition was in every case raised to the fullest extent, and the gases after exposure to it were carefully cooled down to their original temperature.

When the experiments were made over water, the whole eudiometer was immersed in a vessel of distilled water, occasionally having an inch depth of oil on the surface (see fig. $2 \dagger$ ); when over mercury, and a longcontinued exposure was required, a bent tube was employed, as at fig. 3, the closed end being immersed in water or oil, to prevent the fusion of the glass which would otherwise have ensued.

Fig. 2.

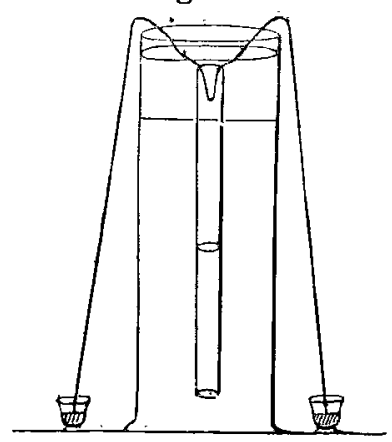

* Transactions of the Cambridge Philosophical Society, vol. i. p. 267.

$f$ In this and in figs. 3 and 5 , the lines leading from the platinum loop to the mereury cups represent copper wires. 
The tubes are much more easily preserved from cracking, and the ignition better kept up with oil on the exterior than with water, but as in many of these experiments I might have been considerably inisFig. 3. led by a crack in the glass, or a bad sealing of the wire, al. lowing a portion of oil to enter the tube, $I$ used water in the greater number of them until I was assured of the phænomena.

The apparatus, fig. 3, is superior in one respect Fig 4. to fig. 2, even for experiments over water, as the wire being situate below the volume of gas, the circulation is more rapid. This object may also be effected by employing the form of eudiometer, fig. 4 , in which the loop of wire is near the centre of the tube, so as to be just above the surface of water in the tube; there are, however, some difficulties of manipulation with this form, which render it practically of less value than fig. 1 .

Binoxide of nitrogen over distilled water contracted differently in proportion to the heat of the wire; in the best experiment it contracted to one-third of its original volume; the residual gas was nitrogen.

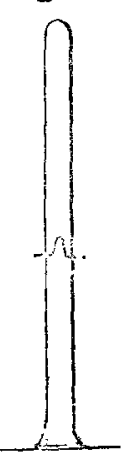
Nitric acid was found in solution in the water.

Over mercury the effects were nearly the same; the mercury was attacked, and the orange fumes of nitrous acid were visible.

Protoxide of.nitrogen was decomposed into nitrogen and oxygen; the volume increased by 0.35 of the original volume; I could not get the full equivalent proportion, or 0.5 of oxygeh.

Carbonic acid underwent no perceptible alteration.

Ammonia incrensed to double its original volume; it was now no longer absorbable by water, and gave three volumes of hydrogen, plus 1 nitrogen.

Olefiant gas contracted slightly, deposited carbon, the residue being hydrogen and olefiant gas, more of the former in proportion to the heat, but I could not succeed in entirely decomposing it.

Nitrogen suffered no change.

Oxygen gave a very slight contraction, amounting to $\frac{1}{50}$ th of its volume; the oxygen employed was very pure, obtained from chlorate of potash and manganese, and also from water 


\section{Mr. Grove on the Decomposition of Water by Heat.}

by electrolysis : no change in properties was perceptible in the oxygen after its exposure to the ignited wire. This contraction $I$ incline to attribute to a slight portion of hydrogen present, which view will, I think, be considered as strengthened by the effect of the ignited wire on hydrogen, to be presently detailed. I at one time thought that the contraction might be due to a slight oxidation of the wire, but it never went beyond a very limited point; nor was the wire altered in size or weight, though it was kept ignited for many hours.

Chlorine over water gave dense white fumes; a grayishyellow insoluble powder accumulated on the sides of the tube near the platinum wire, which appeared of the same nature as the vapours; the deposit was insoluble in cold nitric, sulphuric, or muriatic acid, but dissolved by the last when boiled. The fumes did not, as far as I could judge, affect litmus paper; a barely perceptible tinge of red was indeed communicated to it, but this, I had every reason to believe, was attributable to a slight portion of muriatic acid not absorbed by the water. I have not yet worked out this result, as it is probable, considering the number of experiments that have been made on heated chlorine, that it is a known product, though I cannot find, in several books to which I have referred, any substance answering to it in description, and the field opened by voltaic ignition is so new that each result demands a separate and prolonged examination; if $I$ find that this is an unknown compound I shall probably resume its investigation*.

Cyanogen gave, though in very minute quantities, a somewhat similar deposit, but at its then very high temperature it began to act rapidly on the mercury, and I was obliged to give up the experiment after an hour's ignition. Both these gases require peculiar and novel apparatus for examination by voltaic ignition. It will presently be seen that my whole attention and disposable time were necessarily occupied with certain phænomena to which this class of experiments ultimately led me.

Hydrogen gave a very notable contraction, amounting in some cases to one-tenth of its volume. This was an unexpected result, and I examined it with care. It took place both over water and over mercury; rather more with the former than with the latter. It obtained equally with hydrogen procured by electrolysis from carefully distilled water and pure sulphuric acid; with that procured from common zinc and pure sulphuric acid diluted with distilled water; and with that obtained from distilled zinc and pure diluted sulphuric acid. The contraction was less when the water from which * See Supplemental paper. 
the hydrogen was obtained was carefully purged of air by boiling and the air-pump, but yet there was a notable contraction even when the water had been freed from air to the utmost practicable extent. In the numerous experiments which I made on this subject, the contraction varied from the $\frac{1}{10}$ th to the $\frac{1}{30}$ th of the whole volume.

After many fruitless experiments I traced it to a small quantity of oxygen which I found hydrogen to contain under all circumstances in which I examined it. Phosphorus placed in hydrogen, obtained with the utmost care, gives fumes of phosphorous acid, shines in the dark and produces a slight contraction, but there is after this a further contraction by the use of the ignited wire.

I may cite the following as an easy experiment and simple illustration of the rapidity with which hydrogen appropriates oxygen. Let hydrogen be collected over water well-purged of air; let a piece of phosphorus remain in it until all combustion has ceased, the hydrogen will then be full of phosphoric vapour; fill another tube with water, and pass the hydrogen rapidly into it, the second tube will instantly be filled with a dense white fume of phosphorous acid; the hydrogen having instantly carried with it oxygen from the stratum of warer it has passed.

A very careful experiment was made as follows :-distilled water was boiled for several hours, to this was added onefortieth part by measure of pure sulphuric acid, and it was cooled under the receiver of an air-pump ; it was now placed in two test-glasses, connected by a narrow inverted tube, full of the same liquid: platinum electrodes were placed in each glass, and the hydrogen caused to ascend immediately into the eudiometer tubes; the whole was completed within two or three minutes after the water had been removed from the airpump. Here the ordinary sources of impurity in hydrogen were avoided; no zinc was used, the sulphuric acid was pure, and the quantity was so small, that, had it not been pure, the error could bave been but very trifling. The hydrogen so obtained, contracted in volume $\frac{1}{26}$ th ; hydrogen prepared in the same way, and exposed to phosphorus, gave dense white fumes; the phosphorus was luminous in the dark for more than an hour, and the contraction (temperature and pressure being carefully examined) was $\frac{1}{90}$ th ; the amount of contraction by the wire would of course equal three times the volume of oxygen mixed with the hydrogen, consequently the oxygen would be $\frac{1}{78}$ th of the whole volume; the platinum wire induces therefore a greater absorption of oxygen than the phosphorus, unless the volume of hydrogen is increased by the phosphoric 
vnpour; the sequel of this paper will render it probable that even the ignited wire does not and cannot induce combination of all the oxygen existing in the hydrogen.

I have looked into the papers of MM. Berzelius and Dulong, and of M. Dumas on the equivalent weight of hydrogen. The latter contains a most careful experimental investigation, and is by far the best determination we have; although it is lot there mentioned that hydrogen contains oxygen, yet a correction is made for the air contained in the sulphuric acid employed، M. Dumas does not state how the quantity of that alr is calculated. There can be no question that nothing approaching in elaborate care to these experiments has been yet performed on the subject; but with the fullest consciousness of M. Dumas' skill, I have, in all my experiments, perceived such an inveterate tendency of hydrogen to possess itself of oxygen, that I cannot help entertaining some doubts whether we have yet the real weight of hydrogen within the assigned limits of error.

It is difficult to see how hydrogen can be absolutely deprived of oxygen which has once existed in it; neither an oxidable metal as zinc, or an ignited inoxidable metal as platinum, getting rid of all the oxygen, and phosphorus, if it does so, replaces it by its own vapour. The near approach, however, of the equivalent of hydrogen, as determined by M. Dumias, to the ratio of whole numbers, renders it probable that it is a very close approximation to the truth.

I have not been able to detect nitrogen in the hydrogen, but the probability is that a slight quantity also exists in it. Whether the oxygen proceeds from portions of air still remaining in solution in the liquid from which the air is exhausted, or whether it is a part of the water actually decomposed, but of which the oxygen is not absorbed by the zinc, is a question to resolve which further experiments are necessary.

Hydrogen and carbonic acid mixed in equal volumes were readily acted on by the ignited wire; they contracted to 0.48 of the original volume; the residue was carbonic oxide; one equivalent of oxygen had therefore united with the hydrogen; and the slight additional contraction was probably due to the further combination of hydrogen with oxygen, as above stated.

Carbonic oxide exhibited a remarkable effect, and one which, coupled with the last experiment, gave rise to considerations which mainly led to the results to be detailed in the body of this paper. Carbonic oxide, very pure and carefully freed from carbonic acid, was exposed to the ignited wire over distilled water; the gas increased in volume in one experiment to one- 
thirl of its original volume, in the greater number of instances to one-fifth: this increase depended upon the intensity of ignition, which it was very difficalt to maintain at its maximum on account of the frequent fusions of the platinum wires.

Here again I had a long research and many erroneous guesses, which I need not detail. The effect dirl not take place with perfectly dry gas over mercury, and I thence was led to attribute it to some combination with aqueous vapour; the increase turned out to be occasioned by the formation of carbonic acid. By agitation with canstic potash or lime water the gas was reduced to exactly its original bulk, but it was now found to be mixed with a volume of hydrogen equal to the volume of carbonic acid by which it had been increased; it was thus perfectly clear that half a volume or one equivalent of oxygen derived from the vapour of the water, had combined with one volume or equivalent of carbonic oxide, and formed one volume or equivalent of carbonic acid, leaving in place of the carbonic oxide with which it had combined, the one volume or equivalent of hydrogen with which it had been originally associated.

Comparing the last experiment, viz. that of mixed carbonic acid and hydrogen with this, I was naturally struck with the curious reversal of affinities under circumstances so nearly similar; in the one case, hydrogen taking oxygen from carbonic acid to form water and leaving carbonic oxide; in the other, carbonic oxide taking oxygen from water to form carbonic acid and leaving hydrogen.

I thought much upon this experiment; it appeared to me ultiniately that the ignited platinum had no specific effect in producing either composition or decomposition of water, but that it simply rendered the chemical equilibrium unstable, and that the gases then restored themselves to a stable equilibrium according to the circumstances in which they were placed with regard to surrounding affinities; that if the state of mixed oxygen and hydrogen gas were, at a certain temperature, more stable than that of water, ignited platinum would decompose water as it does ammonia.

This is a very crude expression of my ideas, but we have no language for such anticipatory notions, and I must adapt existing terms as well as I am able.

It now appeared to me that it was possible to effect the decomposition of water by ignited platinum; that, supposing the atmosphere of steam in the immediate vicinity of igniled platinum were decomposed, or the affinities of its constituents loosened, if there were any means of suddenly removing this atmosphere I might get the mixed gases; or secondly, if, as 
appeared by the last two experiments, quantity had any influence, that it might be possible so to divide the mixed gases by a quantity of a neutral ingredient as to obtain them by subsequent separation (or as it were filtration) from the neutral substance. Both these ideas were realized.

'To effect the first object, after, as usual in such circumstances, much groping in the dark, I cemented a loop of platinum wire in the end of a tube retort similar to fig. 3, and covered it with asbestos, ramming this down so as to form a plug at the closed extremity of the tube, the platinum wire being in the centre. My object was, by igniting the platinum wire, to drain the water out of the asbestos, and the ignited wire being then in an atmosphere of steam, I hoped the water would by capillary attraction keep constantly oozing down to the platinum wire as the steam or decomposed water ascended. The experiment did not succeed; the water established a current through the asbestos by washing away fine particles, and the phænomena of ordinary ebullition took place, unless the intensity of the battery was very much exalted, when a very slight decomposition was perceptible, which I attributed to electrolysis. This experiment, however, suggested another which did succeed. In one or two cases the asbestos plug became compressed above the platinum and so choked up the tube that the wire suddenly fused. It now occurred to me that by narrowing the glass tube above the platinum wire I had the result at iny command, as the narrow neck might be made of any diameter and length, so as just to allow the water to drip or run down as the steam forced its way up; a tube was so formed, and is shown with its accompaniments at fig. 5 .

Fig. 5.

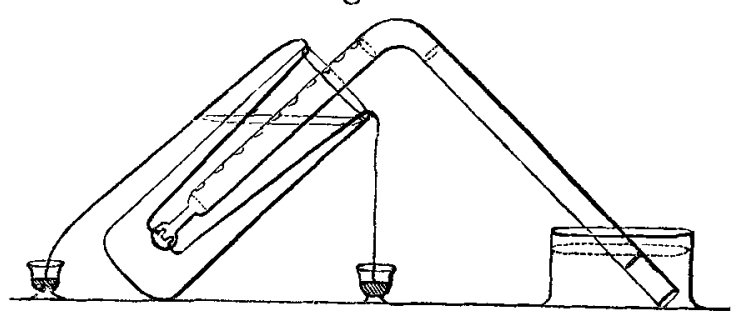

'The result of this experiment was very striking: when two cells of the nitric-acid battery were applied the air was first expanded and expelled, the water then soon boiled, and at a certain period the wire became ignited in the steam. At this instant a tremulous motion was perceptible, and separate bubbles of permanent gas of the size of pin-heads ascended, 
and formed a volume in the bend of the tube. It was not a continuous discharge of gas as in electrolysis, but appeared to be a series of rapid jerks; the water, returning through the narrow neck, formed a natural valve which cut off by an intermitting action portions of the atmosphere surrounding the wire; the experiment presented a novel and indescribably curious effect. The gas was oxyhydrogen. It will occur at the first to many of those who hear this paper read, that this effect might be derived from electrolysis. No one seeing it would think so for a moment; and although I shall by my subsequent experiments, I trust, abundantly negative this supposition, yet as this was my first successful experiment on this subject, and is per se an interesting and striking method of showing the phænomenon of decomposition by heat, I will meption a few points to prove that the phænomenon could not be occasioned by electrolysis.

'To account for it by electrolysis, it must be supposed that the wire offered such a resistance to the current that this divided itself, and the excess of voltaic power passed by the small portion of water which trickled down, instead of by the wire.

In the first place, the experiment was performed with distilled water, and only two cells of the battery employed, which will not perceptibly decompose distilled water.

2ndly. No decomposition took place until the instant of ignition of the wire, though there was a greater surface of boiling water exposed to the wire before than after the period of ignition.

3rdly. A similar experiment was made, but with the wire divided in the centre so as to form two electrodes, and the water boiled by a spirit-lamp; here the current had no wire to conduct any part of it away, but the whole was obliged to pass across the liquid, and yet no decomposition took place, or if there were any it was microscopic.

4thly. When, instead of oil, distilled water was used in the outer vessel*, even the copper wires, one of which would form an oxidable anode, gave no decomposition across the boiling water outside, while the ignited wire inside was freely yielding mixed gases.

5thly. 'To prevent the water from being the shortest line for the current, I repeated the experiment with a perfectly straight wire (fig. 6). The result was precisely the same, but the experiment is more difficult; as a certain length of

* January 8.-I have since found that the exterior tube of oil or water may be dispensed with in this experiment, as the water which trickles down prevents the fusion of the glass. 
wire is necessary, the sealing is more troublesome, and the size of the bulb is much more difficult to adapt to the production of steam in exactly the requisite quantity; the straight wire being more suddenly extinguished and more easily fused: with careful manipulation however it succeeds equally well with the former experiment.

I might add other experiments and arguments, but $I$ believe when Fig. 6.

the remainder of this paper has been read, that the above will be thought scarcely necessary.

I now directed all my efforts to produce the effects by heat alone without the battery. I will mention a few of my unsuccessful attempts, as it will save trouble to future experimenters. I sealed a platinum wire into the extremity of a curved tube, filled the latter with water, and applied a strong heat by the blowpipe to the projecting end of the wire, hoping that the conducting power of the platinum, although inferior to that of most other metals, was sufficiently superior to that of glass to enable me to ignite the portion of the wire within the tube, and thus surround it with an atmosphere of stenm; the water however all boiled off from the glass; nor could I succeed in igniting the platinum by heat from without. A similar failure occurred when, on account of its superior conducting power, a gold wire was substituted for that of platinum.

I sealed spongy platinum and bundles of platinum wire into the ends of Bohemian glass tubes, closing the glass over them, and then filling the tubes with water and heating the whole extremity; but the water boiled off from the glass, and the platinum could not be made to attain a full incandescence.

After many similar trials I returned to the battery, and sought to apply it in a manner in which electrolysis could not possibly take place. I had hoped, as I have above stated, to obtain a residual decomposition of water by masking or diluting the gases by a neutral substance. I therefore tried the following experiment: a tube similar to fig. 1 was filled with water which had been carefully freed from air by long boiling and the air-pump; it was then inverted in a vessel of the same water, and a spirit-lamp applied to its closed extremity, until the upper half was filled with va-

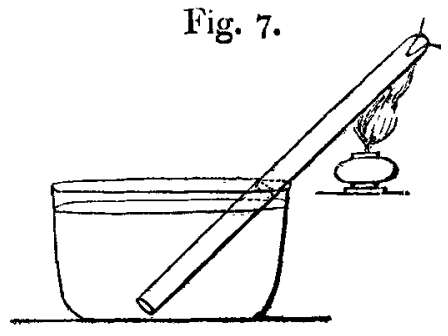


pour (fig. 7). The wire was brought to a full ignition by the battery, and kept ignited for a few seconds; connexion was then broken and the lamp removed, so that the water gradually ascended. A bubble of the size of a large mustard. seed was left in the extremity of the tube, and I was much gratified at finding that when this was caught by a lighted match at the surface of the water-trough it detonated. The experiment was then repeated, continuing the ignition for a longer time, but the gas could not be increased beyond a very limited quantity ; indeed it was not to have been expected, as supposing it to be mixed gas, recombination of the excess would have taken place, and the fact of any uncombined gas existing when exposed to incandescent platinum, will doubtless surprise those who hear it for the first time.

The experiment was repeated as at first and the bubble transferred to another tube; the wire was then again ignited in vapour, another bubble was instantly formed and transferred, and so on, until after about ten hours' work sufficient gas was collected for analysis; this gas was now placed in an eudiometer, it detonated and contracted to 0.35 of its original volume; the residue being nitrogen. The experiment was repeated several times with the same general results, the residue sometimes containing a trace of oxygen,

Here electrolysis was out of the question; the wire wns ignited in (if I may use the expression) dry steam, the upper part of the tube being far above the boiling-point, and of course perfectly transparent; if not an effect of heat, it must have been a new function of the electric current, at least one hitherto unknown.

As the voltaic arc and electric spark afford heat of the greatest intensity, I tried a succession of electric sparks from platinum wires through steam in the apparatus fig. $s$, the water, as in all my experiments, having been previously purged of air (to save circumlocution I will in future call it prepared water). The sparks were taken from the hydro-electric machine of the London Institution; they had in the steam a beautiful crimson appearance; on cooling the tube a bubble was perceptible, which detonated by the match.

Fig. 8.

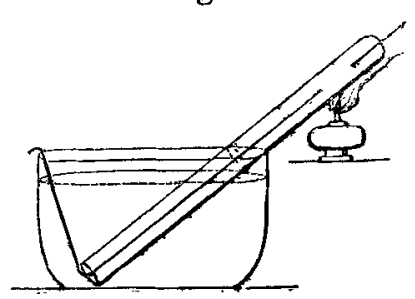

As in the previous experiments, a whole day's work did not increase the bubble, but when it was transferred another instantly formed; the gas was similarly collected; it detonated 


\section{$32 \mathrm{Mr}$. Grove on the Decomposition of Water by Heat.}

and contracted to 0.4 of its original volume; the residue was nitrogen with a trace of oxygen.

This experiment will again surprise by its novelty; the very means used in every laboratory to combine the mixed gases and form water, here decompose water*. From a vast number of experiments which I have made on the voltaic and electric disruptive discharges (which are I believe similar phænomena, differing only in quantity and intensity), I believe the decompositions produced by them are the effects of heat alone, and this experiment was therefore to my mind a repetition of the last under different circumstances; others however may think differently. 'This experiment also I several times repeated.

By counting the globules given off, and comparing a certain number of them with the average volume of steam in the last two experiments, an attempt was made to ascertain what proportion of water could be decomposed by an ignited platinum wire in aqueous vapour, or, which amounts to a corollary from this proposition, what degree of dilution would enable mixed gas to exist without combustion in an atmosphere of steam exposed to an ignited platinum wire. The proportion in an experiment in which the globules were so counted, was 1 to 2400 ; the probability is however that different temperatures of the platinum wire would give different volumes of gas so decomposed, the volume being greater as the wire is more intensely ignited.

Although there was no known effect of electricity which could produce the phænomenon exhibited by the last two experiments, and it was in any event new, still, firmly convinced that it was an effect of heat, I again determined to attempt its production by heat alone, and without the use of the battery. I procured a tube of silver 9 inches long and 0.4 inch diameter; at the extremity of this was a platinum cap to which a smaller tube, also of platinum, was soldered. This platinum tube was closed at the end and soldered with gold solder. The apparatus was filled with prepared water; the water was boiled in the tube to expel the air from the narrow tube and any which might have adhered to the vessel;

Fig. 9.

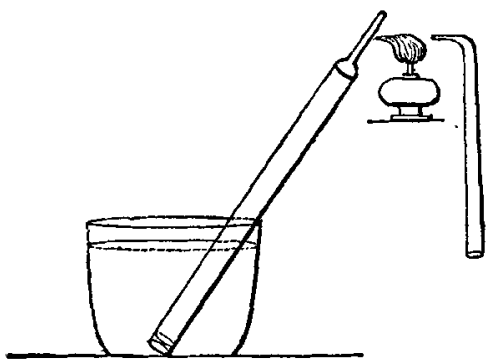

- I need scarcely point out the distinction, in fact, between this experiment and those in which liquid water has been decomposed by the electric spark. See Supplemental Paper. 
the tube was then, when full of hot water, inverted into water, and the flame of a common blowpipe made to play against the platinum tube (fig. 9) until a white heat was obtained. Upon inverting it under water, a bubble of the size of a mustardseed rose to the surface, which gave a very feeble detonation with the match. Similar bubbles were collected as before, and the gas in an eudiometer contracted to 0.7 . On repetition the experiment did not succeed so well, and upon several repetitions it sometimes succeeded and sometimes failed, and I should not mention it but that it was the first experiment which gave me, although not very satisfactorily, the effect of decomposition by heat alone. The reason of its uncertainty I believe to have been the want of a sufficiently intense heat, as I dared not venture on account of the gold solder to push the ignition very far; in fact, I subsequently fused the extremity and spoiled the apparatus by applying the oxyhydrogen flame to it; had the platinum tube been welded instead of gold-soldered, it would donbtless have succeeded better. I should state that the object of the silver tube was to prevent the chance of recomposition by the catalytic effect of a large platinum surface; to have, in short, a small portion of platinum exposed to the steam, and that at a high temperature: œconomy was also no indifferent consideration. This experiment, although, coupled with the previous ones, tolerably conclusive, did not satisfy me, and I attacked the difficulty in another manner. The experiment (fig. 5) induced me to believe that if I could get platinum ignited under water so as to be in an atmosphere of steam, decomposition would take place; and M. Boutigny's experiments on the spheroidal state of water led me to hope I might keep platinum for some time under conditions suitable for $\mathrm{my}$ purpose.

After a few failures I succeeded perfectly by the following experiment. The extremity of a stout platinum wire was fused into a globule of the size of a peppercorn, by a nitricacid battery of thirty cells; prepared water was kept simmering by a spirit-lamp, with a tube filled with water inverted in it; charcoal being the negative terminal, the voltaic arc was taken between that and the platinum globule until the latter was at the point of fusion; the circuit was now broken, and the highly incandescent platinum plunged into the prepared water: separate pearly bubbles of gas rose into the tube, presenting a somewhat similar effect to experiment (fig. 5 ). The process was repeated, the globule being frequently plunged into the water in a state of actual fusion; and when a sufficient quantity of gas was collected it was examined, it detonated,

Phil. Mag. S. 3. Vol. 31. No. 205. July 1847. 


\section{Mr. Grove on the Decomposition of Water by Heat.}

leaving 0.4 residue; this was as usual nitrogen with a trace of oxygen. A second experiment gave a still better result, the gas contracting to 0.25 of its original volume.

On making the platinum negative and the charcoal positive, a very different result followed: the carbon was, as is known to electricians, projected upon the platinum; and the gas in this case was mixed with carburetted hydrogen and carbonic oxide. I know no experiment which shows so strikingly the different effects at the disruptive terminals as this; when the platinum is negative it gives much carbonic gas, when it is positive, not a trace (the gas was delicately and carefully tested for it); nay, more, by changing the platinum from negative to positive the carbon is instantly removed, and in a single experiment the platinum becomes perfectly clean.

Here then I produced very satisfactorily decomposition by heat; it is true, the battery was used, but used only as a means of fusing the platinum, as this was, as soon as fused, entirely separated from the circuit and could have no possible voltaic action. Wishing however altogether to avoid the use of the battery, I repeated this experiment, employing as my means of fusing the platinum the oxybydrogen blowpipe; the experiment was equally successful, perhaps more so, as the manipulation was more easy.

I could readily by this means collect half a cubic inch or more of the gas; when detonated, the residue of nitrogen averaged 0.35 of the original volume.

In carefully watching this experiment, 1 observed that at first a rapid succession of bubbles ascended into the tube from the incandescent platinum, it then became quiescent; the spheroidal state was assumed by the water and no gas ascended; on losing the spheroidal state a sudden hiss was heard, and a single bubble ascended into the tube. I determined to examine separately the gas from the platinum before and after the quiescent state; to effect this I placed two inverted tubes in the capsule with the orifices near each other; the platinum at the point of fusion was immersed under one tube, say tube $A$, and as soon as the ascent of bubbles ceased, it was removed across to tube $B$, and the last bubble then entered that tube; the gases from each tube were separately analysed, and tube $\boldsymbol{A}$ gave nearly all detonating gas, the residue being only 0.2 ; tube $B$ gave none; the gas collected in it was nitrogen, with a trace of oxygen.

In order to examine the effect of an oxidable metal under similar circumstances, I fused by the oxyhydrogen blowpipe the end of a stout iron wire, plunged it into prepared water and collected the globules of gas; no oxygen was given off, 
or at least no more than I have always found to accompany hydrogen, which with a small residue of nitrogen was the gas given off in this experiment.

[To be continued.]

V. Invention of Fluxions. By Chardes Richard Weld, Esq.

To the Editors of the Philosophical Magazine and Journal.

GENTLEMEN,

T $N$ the course of my researches in the archives of the Royal Society, with reference to a history of the Society which I am compiling, I have been much struck with a very remarkable discrepancy on a most important point, connected with the celebrated dispute of the invention of fluxions, between the original Minutes of the Society and the statements of writers on this subject.

Sir David Brewster and Professor De Morgan, following others, state that at a meeting of the Society held on the 20 th of May 1714, a resolution was inserted in the Minutes, that "s it was never intended that the report of the committee was to pass for a decision of the Society*." This alludes to the report presented by the committee appointed by the Society to determine the question of the invention of fluxions. Now the exact words of the minute are these:-

"It was not judged proper (since this letter was not directed to them $\dagger$ ) for the Society to concern themselves therewith, nor were they desired so to do; but that if any person had any material objection against the Commercium or the report of the committee, it might be reconsidered at any timef."

There is nothing here to show that the Society resolved (and this is the word Mr. De Morgan uses) upon repudiating the report of their committee; so far from this, the opposite conclusion is at once obvious, which is in keeping with the original resolution of the Society adopting the report of their Committee, nemine contradicente. The point is of great moment; for had the Society come to the resolution as represented, a strong case would be made out against Newton. I have examined the Minutes of the meeting in question with the greatest care, and confidently assert that there is no other allusion to the dispute between Leibnitz and Newton. In conclusion, I wish to state that it is at the request of some of

* See Life of Newton by Brewster, p. 211, and Life by De Morgan, p. 93.

$\uparrow$ Alluding to a letter of Leibnitz to Clamberlayne, complaining of the report of the committee.

$\ddagger$ Journ. Book, vol, xi. p. 431. 